City University of New York (CUNY)

CUNY Academic Works

\title{
Board 121: Development of a Create-a-Lego-Engineer Activity to Examine Students' Engineering Identity
}

\author{
Kelli Paul \\ Indiana University - Bloomington \\ Euisuk Sung \\ CUNY New York City College of Technology \\ Adam V. Maltese \\ Indiana University - Bloomington \\ Karen Miel \\ Tufts University \\ Merredith D. Portsmore \\ Tufts University
}

\section{How does access to this work benefit you? Let us know!}

More information about this work at: https://academicworks.cuny.edu/ny_pubs/834

Discover additional works at: https://academicworks.cuny.edu

This work is made publicly available by the City University of New York (CUNY).

Contact: AcademicWorks@cuny.edu 


\section{Board 121: Development of a Create-a-Lego-Engineer Activity to Examine Students' Engineering Identity}

\section{Dr. Kelli Paul, Indiana University}

Dr. Kelli Paul is a postdoctoral researcher in science education at Indiana University. She received her Ph.D. in Educational Psychology specializing in Inquiry Methodology from Indiana University in 2006. She managed a consulting business for 10 years working on evaluations that focused primarily in the areas of education and STEM for middle and high school students, especially women and minority students. Her research interests include student engagement and interest in STEM and STEM careers as well as the development of instruments and evaluation tools to assess these constructs.

\section{Dr. Euisuk Sung, Indiana University}

Euisuk Sung is a postdoctoral researcher at Indiana University. He earned a Ph.D. degree in Engineering and Technology Teacher Education at Purdue University. He has computer science degree and worked as a computer software developer for three years. then he served as an engineering and technology educator in high school for 9 years in South Korea. Currently he is working in NSF Funded project, titled TRAILS. His research interests are design cognition, maker education, computer science education, and all about STEM education.

\section{Dr. Adam V. Maltese, Indiana University}

Associate Professor of Science Education

\section{Ms. Karen Miel, Tufts University}

Karen Miel is a PhD student in STEM Education at Tufts University. Karen served as the Director of Research and Innovation at the science center CuriOdyssey and the Education Director of the Palo Alto Junior Museum and Zoo after teaching elementary and middle school. Her research focuses on elementary students' reasoning and decision-making in collaborative engineering design.

\section{Dr. Merredith D Portsmore, Tufts University}

Dr. Merredith Portsmore is the Director for Tufts Center for Engineering Education and Outreach (www.ceeo.tufts.edu). Merredith received all four of her degrees from Tufts (B.A. English, B.S. Mechanical Engineering, M.A. Education, $\mathrm{PhD}$ in Engineering Education). Her research interests focus on how children engage in designing and constructing solutions to engineering design problems and evaluating students' design artifacts. Her outreach work focuses on creating resources for K-12 educators to support engineering education in the classroom. She is also the founder of STOMP (stompnetwork.org), LEGOengineering.com (legoengineering.com), and the online Teacher Engineering Education Program (teep.tufts.edu). 


\section{Development of a Create-a-LEGO-Engineer Activity to Examine Students' Engineering Identity (Work in Progress)}

\section{Introduction}

One of the primary goals of K-12 engineering education is to increase the number of students interested in or pursuing engineering-related studies [1-2]. Many engineering education researchers have identified that young students' conceptions of engineering play a significant role in their career choice and persistence in engineering studies [3-4]. In 2018, underrepresentation within engineering careers persists such that $15.9 \%$ of engineers were women, $6.5 \%$ were African American, and $8.9 \%$ were Hispanic, all are less than their representation in the U.S. population [5]. Yet, little is known about how elementary students, particularly students from groups underrepresented in engineering, choose STEM careers [6-7]. Engineering interest declines as youth enter middle school, making elementary school a potentially critical developmental window for bolstering engineering aspirations [8-9].

Our aim was to develop a tool to measure how young students conceive of engineering and themselves as engineers. One popular tool used to measure conceptions of engineering is the Draw-an-Engineer Test (DAET) [10], which is an adaptation of the Draw-A-Scientist Test (DAST) [11]. Unlike previous measures, the DAST did not rely on a student's ability to write or respond to written instruments and capitalized on the belief that most children like to draw [12]. Children's drawings are rated on the presence/absence of certain characteristics. These ratings provide information about their conceptions and stereotypical images of scientists. However, the DAET does not provide information as to whether students see themselves as an engineer or envision engineering as a future possible self. While the drawings from the DAET provide information regarding perceptions of engineers and engineering, we wanted to capture whether students can see themselves as engineers, rather than simply assessing students' impressions and perceptions of others as engineers. As an alternative, we developed the Create-a-LEGO-Engineer (CALE) activity in which students create themselves as engineers and create a scene to show the work they are doing as engineers. In this paper we describe the evolution of the CALE activity through three phases of development and discuss preliminary findings from each phase.

We drew from the LEGO Serious Play (LSP) method which is grounded on the premise that hands-on learning results in a deeper understanding of the world and oneself in it [13]. The theoretical principles that guide LSP are play, constructionism, flow, hands-mind connection, and the use of metaphors [14]. Participants have opportunities to create and refine abstract mental ideas through the iterative process of making with physical artifacts [15]. Drawing from the LSP method, we designed the CALE activity to be more interactive and engaging for students than the DAET assessment tool. The use of LEGO blocks in the CALE activity allows students to modify and explore multiple ideas without the concern for making changes in the drawing; rather, they simply move the bricks around to create something new. Additionally, using LEGO bricks is advantageous in that they: 1) are familiar to most students; 2) are easy to use even without prior experience; 3 ) do not require prerequisite artistic skills or self-confidence; and 4) afford symbolization (e.g., a LEGO brick can represent anything that you want it to). 


\section{Methods}

The CALE activity was developed as part of a multi-year NSF-funded project. During the development of the activity, we solicited $3^{\text {rd }}-5^{\text {th }}$ grade teachers in the Midwest United States to determine their interest in using the activity with their students as a supplement to their science instruction. Eleven teachers from two schools expressed interest. The two schools were located in two suburban school districts. Ten teachers represented School A and one teacher represented School B. The majority of students in both schools were White/Caucasian, followed by multiracial, Hispanic, and other (district level data statistics), and these patterns were observed by researchers in the classrooms (demographic data were not collected on students). In all, 265 students participated in the activity.

Two researchers facilitated the CALE activity in the classrooms. The activity ranged in duration from 30-50 minutes, depending on classroom schedules. After completing the activity in each classroom, researchers made field notes and discussed aspects of the activity that did and did not work. Because the activity was in development, we refined and updated the activity as needed. Four types of data were collected during the pilot tests: 1) written notecards describing the engineers and scenes; 2) photographs of the LEGO creations; 3) videos of the overall activity and students describing their final creations; and 4) field notes that included student feedback collected at the end of the activity. With the exception of field notes which were collected in every classroom, the other data were collected to varying degrees in each classroom.

\section{Phases of Activity Development}

The overall activity itself remained similar across the first two phases of development, with the primary revisions focusing on the order of the instructions and activity. Figure 1 presents a flow chart depicting the order of instructions during Phase 1 and 2. In both phases, students began by creating themselves as a LEGO Person (hereafter LEGO Me). Once they had created their LEGO $\mathrm{Me}$, they were directed to create their LEGO scene with the following instructions: "Imagine that you and your LEGO Me are engineers. Think about the types of activities or engineering work that you might do. Now, using your LEGO bricks, create a scene to depict what your LEGO Me is doing." During the instructions, we were very conscious not to use the word "build"; rather, we used the words "create", "make", or "design" to avoid cueing the stereotypical image of engineering as "building". Students were instructed to make brief notes on a notecard about what their LEGO Me was doing in the scene by responding to the following prompt: "Describe the engineer you created and what your engineer is doing." The two phases differed as to when students were given the LEGO bricks as well as when students created notes about their scenes.

\section{Phase 1 - Initial Activity}

In the first two classrooms, because LEGO bricks were distributed simultaneously with or slightly before the instructions to create their scene, we observed that students' scene designs often were driven by the LEGO pieces in front of them rather than what their engineer might be doing. We also observed that students' descriptions on their notecards did not describe their scene but only described the actual LEGO person created (e.g., "I created a really pink person" or "A girl with a ponytail and white shirt"). Additionally, at the end of the activity, we observed that some students had misconceptions of engineers, but since the activity was designed as an 
assessment tool, we did not have the opportunity to address this with students. However, based on this observation, we revised the activity in Phase 2 to afford an opportunity to directly address students' (mis)conceptions of engineers.

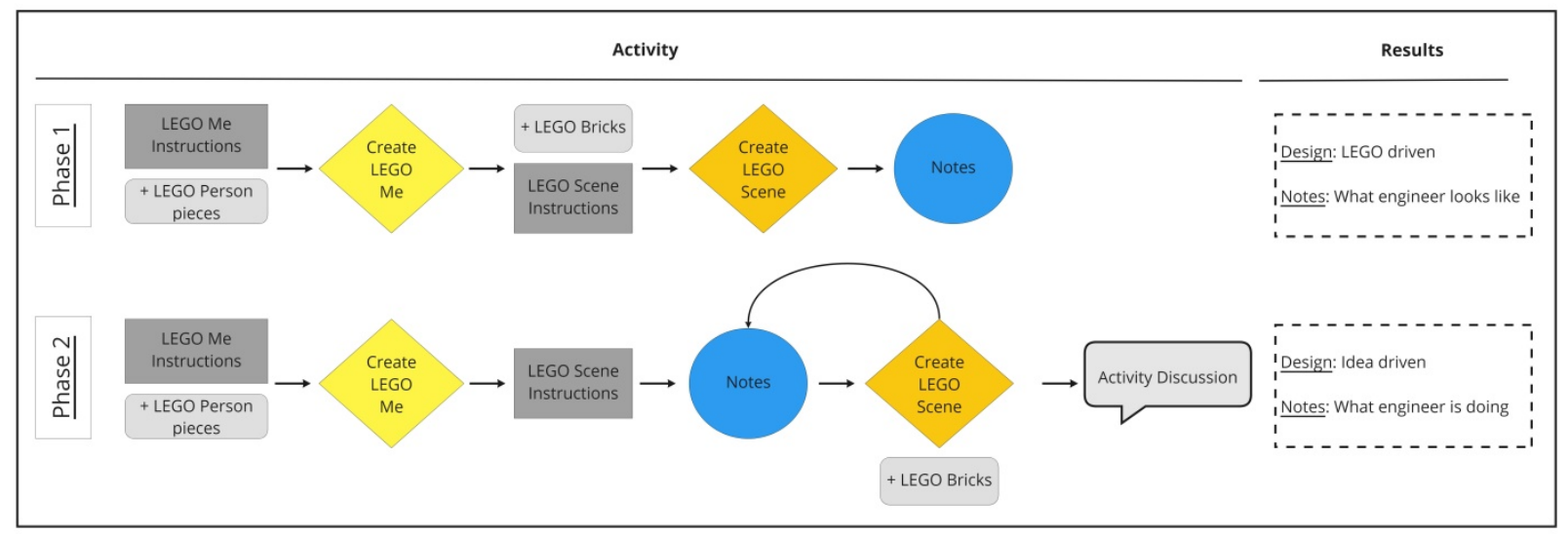

Figure 1. Flow Chart of Order of Activity and Summary of Results

\section{Phase 2 - Revised activity}

Based on observations from Phase 1, we revised the order of the activity so that students made notes about what their engineer would be doing in the scene prior to receiving their LEGO bricks. Students were encouraged to revise their notecard if their scene changed during the activity. We hoped that this would help focus students on seeing themselves as engineers and have their ideas, rather than the LEGO bricks, drive the creation of the scene. We also added a brief time at the end of the activity to talk about what an engineer is and does, the variety of scenes created and how that reflects the variety of engineers, and how students' interests can fit with the many different types of engineers. This shift moved the activity more into the realm of an intervention rather than just data collection alone. The revised version of the activity was used in the remaining nine classrooms. When they completed their scene, we encouraged students to create a brief video using a GoPro camera to describe what their engineer was doing. However, time constraints often resulted in few videos being made. We made concerted efforts in the later classrooms to try and collect these data.

Figure 2 presents examples of created LEGO scenes.

During the revised activity, we noticed that students tended to plan their scene prior to creating, resulting in the activity being more idea-driven than LEGO brick-driven. We also
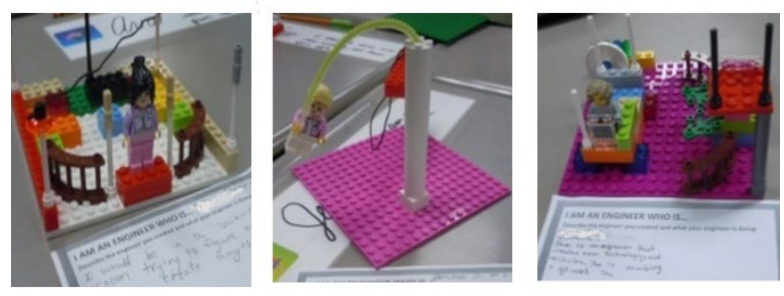

Figure 2. Examples of LEGO scenes. observed that students made changes to their scenes and often noted these on their cards. However, we found that it still was difficult to fully interpret the scene and notecard, especially when students did not record a video description. To try and ensure we understood the scenes when no video data were available, in the last classroom we modified the note card by providing specific prompts to guide students' thinking and description about the scene. Namely, we asked them: 1) Where is your engineer?; 2) What is 
your engineer doing and why?; and 3) Describe two or more things in your scene. This slight modification resulted in more detailed descriptions of the scene created.

\section{Phase 3 - LEGO Me Puppet}

After conducting the activity in 11 classrooms, we encountered a few challenges with the activity. The most difficult challenge was finding LEGO minifigure pieces that reflected the variety of hair, skin, and clothing options that students desired to create themselves as a LEGO person. The lack of variety, especially in terms of gender and ethnic characteristics, precluded some students from being able to accomplish the initial task of creating themselves. When LEGO minifigure pieces were found, there was a significant cost associated with providing them in sufficient quantities to conduct the activity with a classroom of students. We tried to use 3D printing to make custom parts, but the colors of filaments were lacking in diversity and a realistic skin tone palette. Finally, for students, the largest disappointment with the activity was finding out that they would not be able to keep their LEGO Me. As such, we revised the activity modeled after Hynes' Make-an-Engineer [16] such that students create a LEGO Me Puppet. Using 4-inch laser-cut wooden LEGO-style figures with detachable arms fastened with metal brads, students used fabric, yarn, duct tape, markers, and colored paper to decorate their LEGO Me Puppet on one side. On the opposite side, they answered questions about themselves (e.g., skills and interests, problems they would like to solve, and ways of thinking to solve these problems). Figure 3 presents examples of created LEGO Me Puppets. The LEGO Me Puppet can be used as a stand-alone activity or in combination with creating the LEGO scene. Unlike the minifigures, students are able to keep their LEGO Me Puppet at the end of the activity. In combination with the notecards and videos, the LEGO Me Puppet also serves as an assessment tool, but it also has potential as an intervention activity to help students continue to explore engineering as a possible future self.

\section{Preliminary Findings}

Preliminary analysis suggests that students attempted to represent themselves in the LEGO Me and scene and that the CALE elicited students' conceptions of what

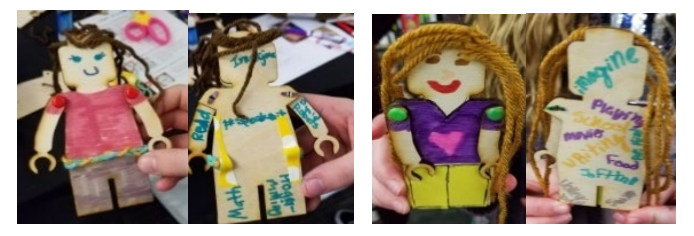

Figure 3. Examples of LEGO Me Puppet. engineers do. Students actively engaged in the activity and tried to create their engineer in their own image. Field notes and photos showed that students identified similarities between themselves and their LEGO engineers (e.g., wearing glasses, similar hair color or shirt color). Many of the LEGO scenes were based on interests and contexts from the students' lives (e.g., coding video games, on the school playground, at gymnastics), suggesting that students were putting themselves into the role of the engineer. Scenes that portray students' living contexts could help inform researchers as to how one's situated context influences conceptions of engineering [17].

All students created a LEGO scene in which their LEGO Me was engaged in what students conceived to be engineering work or activities. While not all LEGO scenes accurately portrayed engineering (e.g., building a cupcake store), those that did tended to overlap in the types of engineering work depicted (e.g., designing, coding) across a variety of engineering fields (e.g., electrical, mechanical, civil, biomedical.). Based on the preliminary findings, the CALE seemed 
to meet its intended purpose of assessing if students could see themselves as engineers and how students envision engineering work.

\section{Conclusions}

Our primary purpose was to develop the CALE as a data collection tool. The CALE seemed to function as intended and provided information about students' perceptions of the work that engineers do and if students could see themselves as engineers. Future work could compare student responses over time to note any changes in perceptions of engineering. The primary challenge would be obtaining sufficiently detailed descriptions to allow comparisons among multiple time points. Additionally, we sought to find distinct features of the CALE compared to similar tools such as the DAET [10] or Make-an-Engineer [16] in order to examine what, if anything, we gained from the CALE as an alternative to these tools. All three tools provide varying levels of information about students' perceptions of the type of work engineers do. While the DAET primarily collects students' stereotypes of an engineer, the Make-an-Engineer and CALE go a step further by connecting the created engineer to the student. While the Makean-Engineer targets older students (e.g., undergraduates) who have a more developed understanding of engineering, the CALE takes into account the emerging understandings that elementary students have and simply asks them to create a visual representation of themselves as a LEGO person that they then imagine as an engineer. The use of LEGO bricks provided a sufficiently low barrier to entry to all students we encountered. As such, students were able to take on the role of an engineer through playful, active making, which may support seeing themselves as possible future engineers $[15,18]$.

During development, we realized that the CALE had potential beyond an assessment tool. While it could be used as a stand-alone assessment tool, the CALE also could serve as the starting point for an intervention; educators could use it to spark discussion about what engineers do and who they are as well as to connect students' personal interests to real-world engineering options. We encountered this during Phase 1, at which point we added a brief discussion at the end of the assessment activity to highlight and expand upon the wide variety of engineering work represented in the LEGO scenes. Because students have an emerging awareness of engineering, such discussion would provide the opportunity to describe engineering fields not represented in created scenes and identify engineering fields of which students are not yet aware. Additionally, information obtained from the CALE could be leveraged to tailor future intervention or classroom activities to student interests, reinforcing possible future selves in engineering. If educators intend to use the CALE as an assessment tool, then its implementation should only focus on data collection and not include feedback or additional discussion. However, if used as both an assessment and intervention, the CALE activity combined with discussion could encourage students to explore engineering and allow them to imagine themselves in the role of an engineer. Continued research is needed to examine the effectiveness of the CALE in both of these capacities.

\section{Acknowledgements}

This material is based upon work supported by the National Science Foundation under Grant No. DRL-1657519. Any opinions, findings, and conclusions are recommendations expressed in this material are those of the authors and do not necessarily reflect the views of the National Science Foundation. 


\section{References}

[1] R.L. Carr, L.D. Bennett IV, and J. Strobel, "Engineering in the K-12 STEM standards of the 50 US states: An analysis of presence and extent," Journal of Engineering Education, vol. 101, no. 3, pp. 539-564, 2012. doi: doi.org/10.1002/j.21689830.2012.tb00061.x

[2] National Research Council, Engineering in K-12 education: Understanding the status and improving the prospects. Washington, DC: National Academies Press, 2009.

[3] N.K. DeJarnette, “America's children: Providing early exposure to STEM (science, technology, engineering and math) initiatives," Education, vol. 133, no. 1, pp. 77-84, 2012.

[4] A.V. Maltese and R.H. Tai, "Pipeline persistence: Examining the association of educational experiences with earned degrees in STEM among US students," Science Education, vol. 95, no. 5, pp. 877-907, 2011. doi: 10.1002/sce.20441

[5] Household Data-Annual Averages: 11. Employed persons by detailed occupation, sex, race, and Hispanic or Latino ethnicity, Labor Force Statistics from the Current Population Survey, United States Department of Labor, Bureau of Labor Statistics, Jan. 2019. [Online] Available: https://www.bls.gov/cps/cpsaat11.htm

[6] W.C. Mau, "Factors that influence persistence in science and engineering career aspirations," The Career Development Quarterly, vol. 51, no. 3, pp. 234-243, 2003. doi: 10.1002/j.2161-0045.2003.tb00604.x

[7] S.L. Dika, and M.M. D'Amico, "Early experiences and integration in the persistence of first-generation college students in STEM and non-STEM majors," Journal of Research in Science Teaching, vol. 53, no. 3, pp. 368-383, 2016. doi: 10.1002/tea.21301

[8] A.V. Maltese and R.H. Tai, "Eyeballs in the fridge: Sources of early interest in science," International Journal of Science Education, vol. 32, no. 5, pp. 669-685, 2010. doi: doi.org/10.1080/09500690902792385

[9] M.T. Wang and J.L. Degol, "Gender gap in science, technology, engineering, and mathematics (STEM): Current knowledge, implications for practice, policy, and future directions," Educational Psychology Review, vol. 29, no. 1, pp. 119-140, 2017. doi: 10.1007/s10648-015-9355-X

[10] M. Knight and C. Cunningham, (2004, June), Draw an Engineer: Development of a tool to investigate students' ideas about engineers and engineering, Paper presented at 2004 Annual Conference, Salt Lake City, Utah. https://peer.asee.org/12831

[11] D.W. Chamber, "Stereotypic images of the scientist: The Draw-a-Scientist Test," Science Education, vol. 67, no. 2, pp. 255-265, 1983.

[12] B.M. Capobianco, H.A. Diefes-Dux, I. Mena, and J. Weller, "What is an engineer? Implications of elementary school student conceptions for engineering 
education," Journal of Engineering Education, vol. 100, no. 2, pp. 304-328, 2011. doi: 10.1002/j.2168-9830.2011.tb00015.x

[13] E. Frick, S. Tardini, and L. Cantoni, "White paper on LEGO® SERIOUS PLAY®: A state of the art of its applications in Europe," Lugano: Università della Svizzera Italiana, 2013. Retrieved from http://www.splay.eu/attachments/article/70/splay_White_Paper_V2 01 _.pdf

[14] S. McCusker, "Lego, seriously: Thinking through building," Intl. J. Knowledge, Innovation and Entrepreneurship, vol. 2, no. 1, pp. 27-37, 2014. Retrieved from http://www.ijkie.org/IJKIE_August2014_SEAN\%20MCCUSKER.pdf

[15] S. Papert and I. Harel, "Situating constructionism," Constructionism, vol. 36, no. 2, pp. 111, 1991. Retrieved from http://namodemello.com.br/pdf/tendencias/situatingconstrutivism.pdf

[16] M.M. Hynes, C. Beebe, A. Hira, A., and K.R. Maxey, "Make-an-Engineer: introduction to engineering activity (P12 Resource/Curriculum Exchange), in Proceedings from the American Society for Engineering Education Annual Conference and Exposition, Salt Lake City, Utah, June 2018. https://peer.asee.org/30783

[17] J.S. Brown, A. Collins, and P. Duguid, "Situated cognition and the culture of learning," Educational researcher, vol. 8, no. 1, pp. 32-42, 1989. doi: 10.3102/0013189X018001032

[18] J. Piaget, The mechanisms of perception. New York, NY: Basic Books, 1969. 